\title{
Scent marking in gerbils and its possible functions
}

\author{
Vladimir S. Gromov
}

ABSTRACT. Behaviors related to scent marking are compared and analyzed in males and females of four gerbil species (Meriones unguiculatus, M. tamariscinus, M. meridianus, and Psammomys obesus) observed in the wild and under semi-natural conditions. Scent-marking activity was found to vary in dependence on species, sex, age, reproductive conditions, social and territorial status of the individuals, and to show seasonal variation. The commonest patterns of scent marking are ventral rubbing and building up of 'signal heaps' with urine and feces. A close association between scent marking and social dominance was revealed in three species ( $M$. unguiculatus, $M$. tamariscinus, $M$. meridianus). Spatial distribution of scent marks was found to be very uneven. Females marked most often the areas near burrow entrances, pathways and feeding sites. Males exhibited a higher rate of scent marking within home ranges of reproducing females. Inter-species differences in scent marking related to a species-specific space use systems and reproductive strategies were revealed. Results of the study partly support the scent-matching hypothesis and the status signaling hypothesis. However, these hypotheses do not predict spatial distribution of scent marks in male gerbils, and do not account for function of scent marking in young individuals as well as an increase of scent-marking activity induced by novelty factors. These findings are more consistent with the hypothesis of home range familiarization. Besides, scent marking in male gerbils could also function as a means of female monopolization.

KEY WORDS: functions, gerbils, home range, rodents, scent marking, territory.

Vladimir S. Gromov [vsgromov@mail.ru], A.N. Severtsov Institute of Ecology and Evolution of the Russian Academy of Sciences, Leninsky pr. 33, Moscow 119071, Russia.

\section{Запаховая маркировка территории у песчанок и ее возможные функции}

\section{В.С. Громов}

РЕЗЮМЕ. Анализируются и сравниваются данные, характеризующие поведение, связанное с запаховой маркировкой территории, у самцов и самок четырех видов песчанок (Meriones unguiculatus, M. tamariscinus, M. meridianus и Psammomys obesus), полученные в результате наблюдений за ними в природе и условиях полувольного содержания. Установлено, что маркировочная активность варьирует в зависимости от вида, пола, возраста, репродуктивного, социального и территориального статуса особей, а также подвержена сезонным колебаниям. Наиболее распространенные способы запаховой маркировки территории у песчанок - маркировка брюшной железой и сооружение “сигнальных сторожков” с мочой и пометом. У трех видов песчанок (M. unguiculatus, M. tamariscinus, M. meridianus) обнаружена тесная взаимосвязь между маркировочной активностью и социальным доминированием. Пространственное распределение запаховых меток очень неравномерно. Самки чаще маркируют входы в норы, тропы и места кормежки. У самцов отмечена повышенная маркировочная активность на участках обитания самок, участвующих в размножении. Межвидовые различия в маркировочной активности связаны, прежде всего, с видовой спецификой использования пространства и разными репродуктивными стратегиями. Результаты исследования частично подтверждают наиболее распространенные гипотезы о сигнальных функциях запаховой маркировки, однако эти гипотезы не объясняют закономерности пространственного распределения запаховых меток у самцов песчанок, функции запаховой маркировки у молодых особей, а также увеличение маркировочной активности в ответ на новизну. Выявленные закономерности в большей степени соответствуют функциям запаховой маркировки, связанным с освоением жизненного пространства. Кроме того, запаховая маркировка у самцов песчанок может служить целям монополизации размножающихся самок.

КЛЮЧЕВЫЕ СЛОВА: функции, песчанки, участок обитания, грызуны, запаховая маркировка, территории. 


\section{Introduction}

Olfactory communication systems are widespread in mammals and serve a wide range of functions. Chemical signals play an important role in determining intraspecies interactions including social dominance and inter-sexual relationships. Most of mammals use specific action patterns to deposit their chemical signals on environmental objects. Such behavior is referred to as scent marking or territory marking. A variety of functional explanations has been proposed for scent marking in mammals including rodents (reviewed by Gosling, 1982 and Roberts, 2007). According to the scentfence hypothesis, scent marks are like a fence around the periphery of the territory to keep intruders out (Hediger, 1949; Müller-Schwarze \& Heckman, 1980). Another hypothesis applies to marking as a means to acquire and maintain an individual or group home range and is related to home range familiarization enhancing the confidence of residents (Mykytowyzc, 1970, 1974). There is also a generally accepted idea that scent marking is a means of olfactory communication. In addition, scent marking is proposed to be a means by which individuals assess the competitive ability of opponents, and resource holders appear to mark to help establish and maintain their status (Gosling, 1982, 1990; Gosling \& McKay, 1990; Gosling \& Roberts, 2001a, b). Roberts (2007) asserted that scent marking is a fundamental component of territorial behavior and of advertising dominance status within social hierarchies. Scent marking is also known to be common among male and female rodents and might be used in male-male competition and as a mechanism for mate attraction. Scent marks of males, in some cases, are signals directed specifically to females (Gosling \& Roberts, 2001a). Females seem to use scent marks of males when choosing mates. The benefits of being chosen as a mate or controlling access to mating opportunities is supposed to account for most scent-marking behavior (Roberts, 2007).

However, not all of the hypotheses received circumstantial support from field and experimental evidence (see, for example, Thomas, 2002; Mech et al., 2003). Recent findings provoke additional questions related to functions of territorial marking, particularly in rodents. Analysis of the literature related to scent-marking phenomenon in mammals revealed that most studies focused mainly on scent-marking behavior of males while scent marking among females has received less research attention. Besides, many mammalian species, including rodents, use different sources of the chemical signals to deposit them on environmental objects, and functional significance of these signals may be also different. The functional variability of various chemical signals in many mammalian species is also not so completely studied.

In this paper, I analyze and compare scent marking in males and females of four species of gerbils (the Mongolian gerbil, Meriones unguiculatus (Milne-Ed- wards, 1867), the tamarisk gerbil, $M$. tamariscinus (Pallas, 1773), the midday gerbil, M. meridianus (Pallas, 1773), and the fat sand rat, Psammomys obesus Cretzschmar, 1828) to make some generalizations. Males and females of every studied species possess a specialized ventral scent gland. The secretion of this gland is used to mark conspecific individuals and environmental objects. Additionally, gerbils use secretion of oral and Harderian glands as well as urine, vaginal secretion, and feces as scent sources (Sokolov \& Gromov, 1998; Gromov, 2000). Besides, these gerbil species show substantial inter-specific variation in their social organization, mating strategy, and space use patterns that are supposed to account for the speciesspecific differences in their scent marking.

Field studies combined with observations under semi-natural conditions revealed that the tamarisk gerbil is a solitary dweller with nocturnal activity (Gromov, 2011a, b). Adults of both sexes occupy individual home ranges. During the mating season (spring - early summer), males did not exhibit territorial behavior. Instead, unstable aggregations of males in the vicinity of ranges of receptive females were regularly found, so that male home ranges overlapped to a great extent. Males apparently engaged in scramble competition for females. Home ranges of females were found to be mutually exclusive, but females actively defended the core areas in the vicinity of their burrows only. Territoriality, i.e. protection of the home range, in males was observed during the non-breeding season (in autumn), when dominance hierarchy among them changed into territoriality or at least a decrease of number of direct contacts between the males with prevalence of mutual avoidance. Both adult males and females regularly mark their home ranges.

According to field studies (Daly \& Daly, 1975; Gromov, 2001), the fat sand rat is also an essentially solitary, but diurnal species. Individual home ranges of adult males and females overlap extensively while maintaining areas exclusive to the same sex, especially among females. However, territorial behavior is not typical of fat sand rats. Home range separation seems to arise from passive avoidance of conspecifics, although aggressive encounters may occur during the period of establishment of home rages. Dominance hierarchy appears to be established among males. Dominant males have larger home ranges than subordinate ones and encounter more receptive females during the breeding season. Adult individuals did not link up one another, and their interactions were relatively infrequent. Both males and females mark their individual home ranges.

Field evidence indicates that the midday gerbil is a gregarious, nocturnal species (Popov et al., 1989; Gromov, 2000). Adult females tend to maintain exclusive home ranges that only partly overlap. Females defend core areas within their home ranges against other mature females. Adult males occupy much larger and unprotected home ranges located corresponding to the location of the females' ranges. Male home ranges 
Table 1. Total numbers of scent-marking events recorded in adult individuals of four species of gerbils during observations in the wild and under semi-natural conditions.

\begin{tabular}{|l|c|c|c|c|c|c|c|c|c|c|}
\hline \multirow{2}{*}{ Species } & \multicolumn{2}{|c|}{$\begin{array}{c}\text { Number of } \\
\text { individuals }\end{array}$} & \multicolumn{2}{c|}{ Ventral rubbing } & \multicolumn{2}{c|}{$\begin{array}{c}\text { Building up of } \\
\text { 'signal heaps, }\end{array}$} & \multicolumn{2}{|c|}{ Genital rubbing } & \multicolumn{2}{c|}{ Chinning } \\
\cline { 2 - 14 } & $m$ & $f$ & $m$ & $f$ & $m$ & $f$ & $m$ & $f$ & $m$ & $f$ \\
\hline Meriones tamariscinus & 7 & 8 & 524 & 197 & 262 & 63 & 0 & 44 & 0 & 0 \\
\hline Meriones meridianus & 12 & 9 & 1043 & 285 & 699 & 309 & 0 & 16 & 2 & 1 \\
\hline Meriones unguiculatus & 20 & 17 & 1100 & 369 & 1660 & 459 & 6 & 11 & 11 & 5 \\
\hline Psammomys obesus & 4 & 6 & 18 & 2 & 57 & 13 & 0 & 0 & 5 & 0 \\
\hline
\end{tabular}

Note: $m$ - males, $f$ - females.

extensively overlap those of other males as well as ranges of the females. During the breeding season, adult males form clans, and the home ranges of clan members mutually overlap. Uniformly distributed home ranges of mature females shared by home ranges of clan males constitute the breeding colony. Usually, a breeding colony consists of several adult males and females, and males belonging to the clan and competing for reproducing females establish a dominance hierarchy. Both adult males and females regularly mark their home ranges.

The Mongolian gerbil is a diurnal species living in extended family groups (Ågren et al., 1989; Gromov, 2008, 2011a, b). As a rule, such groups include one adult male, one or two, less frequently three, adult females, and their offspring. Each family group occupies its own home range (the territory) with clearly established boundaries, marks and protects it from conspecific intruders. Aggressive interactions between members of the neighboring family groups allow correct location of the boundaries between protected territories. A basic feature of the social organization of the Mongolian gerbil is that males usually dominate females, older individuals dominate younger ones, and larger individuals dominate smaller ones among littermates. Dominance is not based upon overt aggressive behaviors. Instead, it is usually demonstrated by short bouts of chasing or threatening. All adult and young members of a family group take part in protection and scent marking of their territory.

In this article, I describe and discuss the results of previously conducted studies (Gromov, 1997, 2000, 2001; Sokolov \& Gromov, 1998) as well as unpublished data obtained due to direct observations of the gerbils in the wild and under semi-natural conditions. I'd like to note that very little is known about scent marking patterns in gerbils except for the Mongolian gerbil whose behavior was studied mainly under laboratory conditions. The main goal of the study is an interspecific comparative analysis of different patterns of scent marking, its seasonal variability and functions in relation to species-specific space use systems. It was not my intention to try to examine all possible functional explanations concerning scent marking, but rather to test the generally accepted hypotheses (Gosling, 1982, 1990; Gosling \& McKay, 1990; Gosling \& Roberts, $2001 \mathrm{a}, \mathrm{b})$ in regard to gerbils.

\section{Material and methods}

The subjects were animals observed in their natural habitats (P. obesus, M. unguiculatus) and under seminatural conditions (M. unguiculatus, M. tamariscinus, M. meridianus $)$ in large open enclosures $(20 \times 20 \mathrm{~m})$ located outdoors at the Chernogolovka field station about $50 \mathrm{~km}$ north-east of Moscow, Russia. Field studies were carried out in the Negev desert, Israel (on $P$. obesus) and in Eastern Siberia, Russia (on M. unguiculatus). For observations in the enclosures, the animals were caught in Eastern Siberia (M. unguiculatus) and the Kalmykia desert, Russia (M. meridianus, M. tamariscinus). To collect data on scent marking and other behaviors of the gerbils, squares of $5 \times 5 \mathrm{~m}$ and of $2.5 \times$ $2.5 \mathrm{~m}$ were laid out within field study sites and in the enclosures, respectively. The corners of the squares were marked by flags with numerical symbols. The positions of the observed gerbils were identified with reference to these flags. In the wild, the number of sedentary individuals living within the study sites was established by trapping, marking, and direct observations. Each captured animal was given an individual mark for identification. This was achieved by coloring the animal fur by a dark hair dye (Ursol D) in a recognizable pattern. Long-distance observations of the animals were carried out using a binocular. Total number of the animals under study is shown in Table 1 . The number and frequency of scent-marking events per home range/enclosure square as well as their spatial distribution were analyzed both in males and females of the species under study. More detail of the material and methods are published elsewhere (Gromov, 1997, 2000, 2001, 2011a; Sokolov \& Gromov, 1998). 
Table 2. Mean frequency of scent marking (per $1 \mathrm{~h}$ of above-ground activity $\pm \mathrm{SE}$ ) in adult males and females of four species of gerbils in the wild and under semi-natural conditions.

\begin{tabular}{|l|c|c|c|c|c|c|}
\hline \multirow{2}{*}{$\begin{array}{l}\text { Species and observation } \\
\text { conditions }\end{array}$} & \multicolumn{2}{|c|}{ Number of individuals } & \multicolumn{2}{|c|}{ Ventral rubbing } & \multicolumn{2}{|c|}{$\begin{array}{c}\text { Building up of } \\
\text { 'signal heaps' }\end{array}$} \\
\cline { 2 - 7 } & $m$ & $f$ & $m$ & $f$ & $m$ & $f$ \\
\hline $\begin{array}{l}\text { Meriones tamariscinus } \\
\text { (in the enclosures) }\end{array}$ & 7 & 8 & $8.4 \pm 0.8$ & $3.5 \pm 1.2$ & $3.8 \pm 0.8$ & $1.0 \pm 0.3$ \\
\hline $\begin{array}{l}\text { Meriones meridianus } \\
\text { (in the enclosures) }\end{array}$ & 12 & 9 & $10.2 \pm 2.6$ & $3.0 \pm 1.5$ & $6.1 \pm 1.2$ & $3.0 \pm 0.6$ \\
\hline $\begin{array}{l}\text { Meriones unguiculatus } \\
\text { (in the wild) }\end{array}$ & 20 & 17 & $6.8 \pm 0.8$ & $2.8 \pm 0.5$ & $9.4 \pm 1.4$ & $4.1 \pm 0.5$ \\
\hline $\begin{array}{l}\text { Psammomys obesus } \\
\text { (in the wild) }\end{array}$ & 4 & 6 & $0.6 \pm 0.3$ & $0.1 \pm 0.1$ & $1.8 \pm 0.5$ & $0.5 \pm 0.3$ \\
\hline
\end{tabular}

Note: $m$ - males, $f$ - females.

\section{Results and Discussion}

\section{Scent sources and related scent-marking patterns}

Due to numerous laboratory studies carried out on the Mongolian gerbil (Thiessen, 1968; Lindzey et al., 1968; Thiessen et al., 1969; Whitsett \& Thiessen, 1972; Owen \& Thiessen, 1973), it is known that both males and females of this species have a ventral sebaceous gland and use its secretion for scent marking. This marking occurs as follows: the animal crawls over some object, its abdomen closely pressed to the surface, and leaves the secretion of the ventral gland on that place (so-called ventral rubbing). In the natural habitat, the objects of ventral rubbing include burrow entrances, soil hammocks, small stones, lumps of ground and other objects both inside the protected territory and along its border.

Surprisingly, numerous laboratory studies of Mongolian gerbils and even observations in enclosures (Payman \& Swanson, 1981) did not reveal the second, also very common and undoubtedly important pattern of scent marking in this species. Observations in the wild showed that, along with ventral rubbing, the gerbils leave a drop of their urine in some places where the substrate is loose enough. Simultaneously, they can also leave 1 to 3 fecal pellets at the same place. After that, throwing the sand beneath its belly by its anterior legs, the animal builds up a conic hillock of the substrate (so-called 'signal heap') covering the drop of urine and fecal pellets (Gromov, 1997, 2011a; Sokolov \& Gromov, 1998). By the way, this kind of scent marking was known long ago in the Great gerbil due to observations of this species in the wild (Dubyansky, 1962).

Along with these two main patterns of scent marking, Mongolian gerbils use genital rubbing and chinning of some objects, but a summarized portion of these scent-marking events does not exceed $1-2 \%$ (Tab. 1).
Thus, the commonest patterns of scent marking in the Mongolian gerbil are ventral rubbing and building up of 'signal heaps'.

Field studies as well as observations in the large open enclosures showed that other gerbil species also possess the ventral gland and use its secretion for scent marking; besides, they also mark their home ranges by building up of 'signal heaps' with urine and fecal pellets (Gromov, 1997, 2000, 2001; Sokolov \& Gromov, 1998). Ventral rubbing was found to be more common for nocturnal species (M. tamariscinus, M. meridianus), while in both diurnal species (M. unguiculatus, $P$. obesus), the second way of scent marking with 'signal heaps' is the most common one (Tab. 1). This difference could be explained by day-time activity of the Mongolian gerbil and the fat sand rat, whose 'signal heaps' seem to serve as both scent and visual marks.

Assuming that ventral rubbing and building up of 'signal heaps' are the main patterns of scent marking in the gerbils, further analysis was focused on these two scent-marking behaviors only.

Scent marking in adult and young individuals

Scent-marking behavior of gerbils generally appear to be sexually dimorphic: both sexes usually mark, but males do so more frequently (Tab. 2). Besides, adults are more active then young individuals, and reproducing animals are more active then non-breeding ones in respect to scent marking (Gromov, 2000). These sexand age-related differences seem to be associated with production of gonadal hormones (Lindzey et al., 1968; Owen \& Thiessen, 1973).

Observations in natural habitats and the enclosures (Gromov, 2000) revealed that young animals start to exhibit scent marking at the age of 5-9 weeks, in dependence on the species (Tab. 3). The earliest marking activity related to building up of 'signal heaps' was revealed in young Mongolian gerbils. Surprisingly, 
Table 3. Age (in weeks) when young and sub-adult individuals of three gerbil species start to exhibit scent marking.

\begin{tabular}{|l|c|c|c|}
\hline Type of scent marking & $\begin{array}{c}\text { M. unguiculatus } \\
(n=28)\end{array}$ & $\begin{array}{c}\text { M. tamariscinus } \\
(n=7)\end{array}$ & $\begin{array}{c}\text { M. meridianus } \\
(n=11)\end{array}$ \\
\hline Building up of 'signal heaps' & 5 & 7 & 9 \\
\hline Ventral rubbing & $10-12$ & $10-12$ & $10-12$ \\
\hline
\end{tabular}

Note: $n$ - number of individuals.

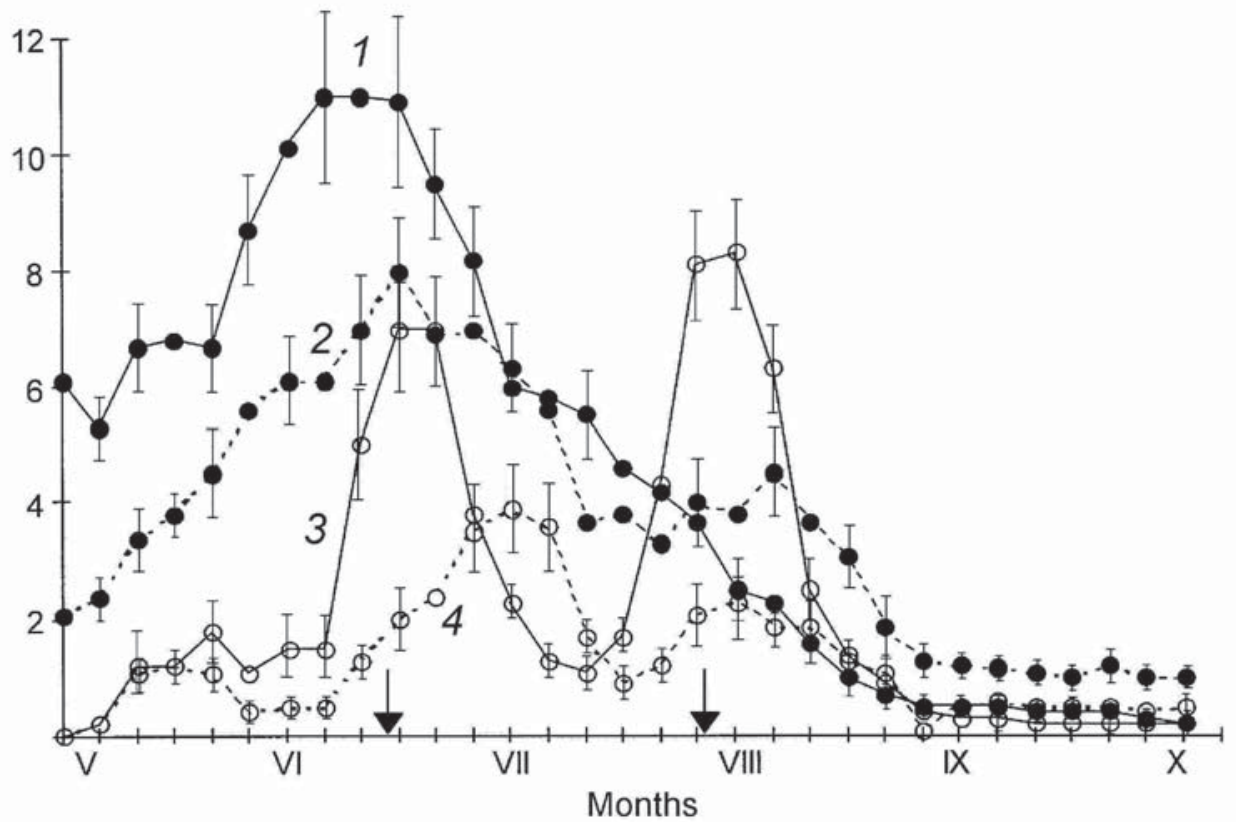

Figure 1. Seasonal changes in scent-marking activity of males $(1,2)$ and females $(3,4)$ of the tamarisk gerbil. 1,3 - ventral rubbing; 2, 4 - building up of 'signal heaps'. Means are given \pm SE. Vertical axis - number of scent-marking events per 1 $\mathrm{h}$ of above-ground activity. Arrows indicate the female receptivity periods.

young midday gerbils which become independent in two weeks after weaning, i.e. at the age of about 5 weeks, start to mark a month later than Mongolian gerbils - a species which delayed sexual maturation and reproductive suppression are characteristic to (Ågren et al., 1989; Gromov, 2000). First signs of ventral rubbing in gerbils were observed at the age of puberty, i.e. at 10-12 weeks. But many Mongolian gerbils of both sexes as well as most males of the tamarisk gerbil at the same age or even older do not take part in reproduction (often until next spring, Gromov, 2000). Nevertheless, this category of animals also exhibits a relatively high level of ventral rubbing.

\section{Seasonal dynamics of scent marking}

Long-term observations of the gerbils in the enclosures revealed that their scent-marking activity shows clearly expressed seasonal variation (Sokolov \& Gromov, 1998; Gromov, 2000). An example of such a seasonal dynamics is shown on Figure 1. Scent-marking activity increased during the breeding season and reached a maximum in spring and the first half of summer, and decreased in autumn and winter.
Seasonal dynamics of ventral rubbing is obviously related to seasonal changes of the integrity of the ventral gland and its functioning (Gromov, 2000). At the non-reproductive period, the rate of ventral rubbing decreased by 10-20 times as compared to the breeding season, but did not fall to a zero level. Evidently, there is some basic level of this kind of scent-marking activity that seems not to be associated with production of gonadal hormones. This low level of spontaneous ventral rubbing sharply increases under influence of gonadal hormones during the breeding season.

The rate of building up of 'signal heaps' significantly decreased during the non-reproductive period but remained on a higher level than the rate of spontaneous ventral rubbing.

The frequency of both patterns of scent marking is found to be tightly linked to female reproductive condition, peaking in frequency during the female receptivity periods (Fig. 1). Thus, scent marking in particular might be used by female gerbils as a reproductive tactic to attract mates.

As for males, demonstration that their marking activity and glandular development are androgen depen- 


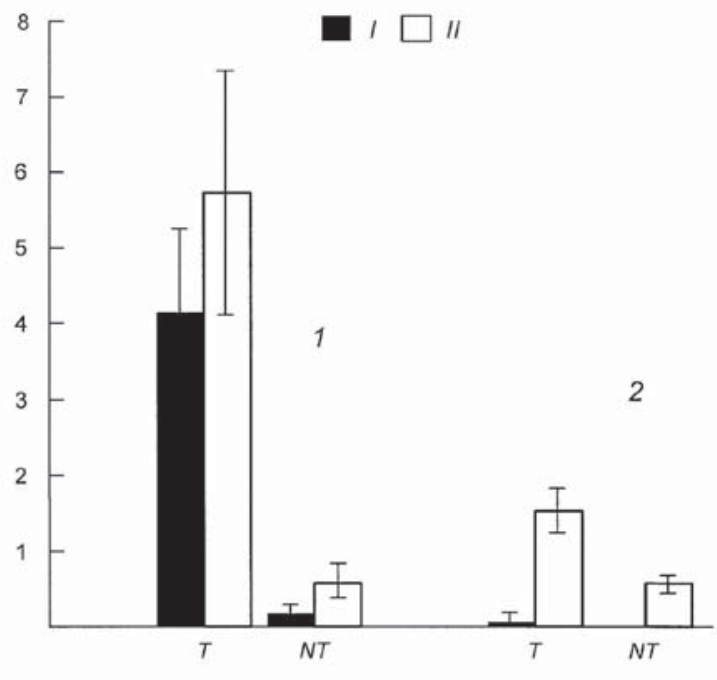

Figure 2. Scent-making rates in Mongolian gerbils in dependence on territory possession. I - ventral rubbing, II building up of 'signal heaps'. 1 - adults, 2 - young individuals. T - territory owners, NT - non-territorial individuals. Vertical axis - number of scent marks per $1 \mathrm{~h}$ of above-ground activity. Means are given $\pm \mathrm{SE}$.

dent (see for review Gosling \& Roberts, 2001a) is used as evidence that scent marking is involved in intrasexual competition (Roberts, 2007).
Scent marking as responsiveness to novelty In many cases, scent marking appears to occur as a response to novelty; that is when a novel, unfamiliar object is introduced into the home range of the individual. Observations in the wild showed that marking activity increased after alteration or disappearance of habitual landmarks caused by rain, wind, or for example, when herds of cows passing through a gerbil colony (Gromov, 2000). These observations lend support to the idea that scent marking might serve to make an area familiar to the animal by a system of olfactory labeling. Indeed, marking activity of individuals occupying a defended territory was found to be as much as 8-10 times higher the marking activity of individuals that did not possess their own home range or lost it as a result of territorial conflicts. In the Mongolian gerbil, such a difference has been found both in adult and young individuals (Fig. 2).

Experiments carried out under semi-natural conditions revealed that the nature of a novel scent affects the magnitude of the response (Gromov, 2000). In these experiments, different sources of novel scents were exposed to midday and Mongolian gerbils in the large open enclosures: plastic bars $(3.0 \times 1.0 \times 0.5 \mathrm{~cm})$, small sand heaps, artificial 'signal heaps' with urine and fecal pellets of unfamiliar conspecifics of both sexes, and small sites $\left(0.1-0.2 \mathrm{~m}^{2}\right)$ with a removed upper ground layer (Fig. 3). These experiments showed that the sites with a removed upper ground layer were investigated and marked much more, irrespectively of their location,

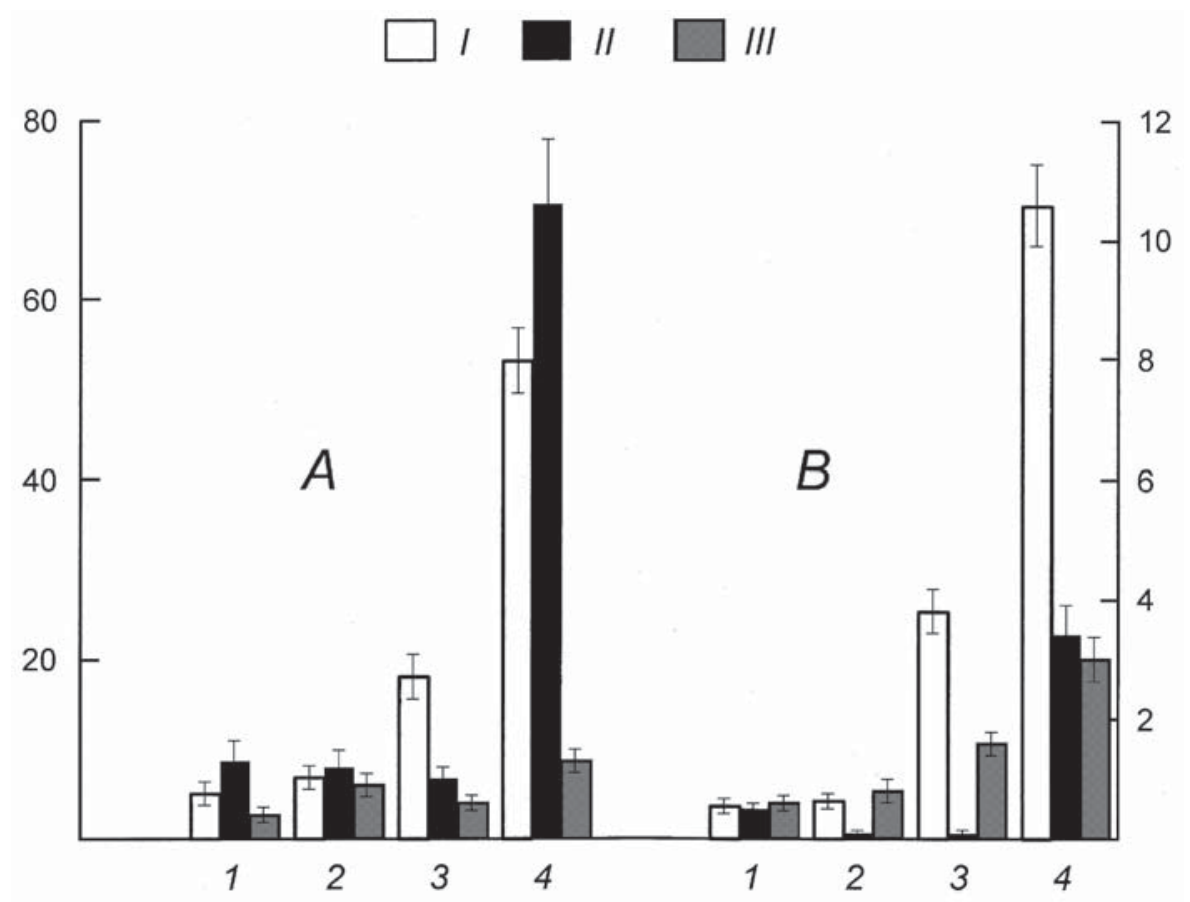

Figure 3. Responses of adult males (A) and females (B) of the midday gerbils to different odor sources. I — investigation, II ventral rubbing, III - building up of 'signal heaps'. 1 - plastic bars, 2 - sand heaps, 3 - artificial 'signal heaps', 4 - sites with removed upper ground layer. Left vertical axis - duration of investigation, s; right vertical axis — number of scent marks per 10-min period of the test. Means are given $\pm \mathrm{SE}$. 


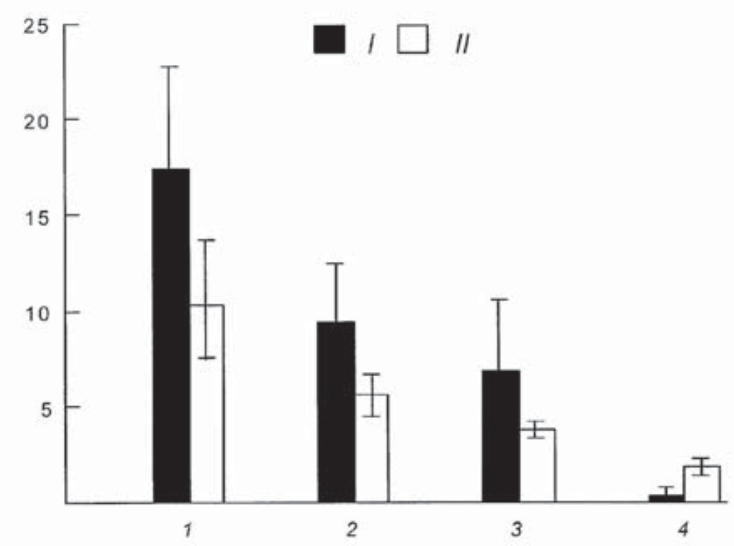

Figure 4. Relationship between social status and scent-marking activity in male midday gerbils. I - ventral rubbing, II - building up of 'signal heaps'. 1-4 - relative social rank. Vertical axis - number of scent-marking events per 1 $\mathrm{h}$ of above-ground activity. Means are given $\pm \mathrm{SE}$.

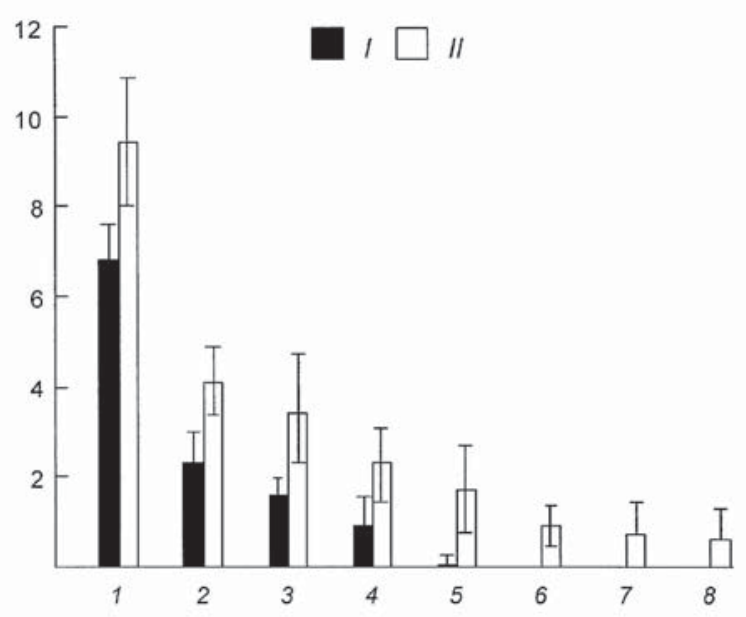

Figure 5. Relationship between social status and scent-marking activity in family groups of Mongolian gerbils. I ventral rubbing, II - building up of 'signal heaps'. 1 adult males, 2 - adult females, 3-8 - relative social rank of sub-adult and young members of family groups. Vertical axis - number of scent-marking events per $1 \mathrm{~h}$ of aboveground activity. Means are given $\pm \mathrm{SE}$.

than any other novel objects including artificial 'signal heaps'. In particular, the number of ventral-rubbing events recorded on the sites with a removed upper ground layer was as much as 4-10 times more, depending on the sex of the animals, than in the presence of any other source of novel scent. Responses of both species (M. meridianus and M. unguiculatus) were found to be similar (Gromov, 2000).

\section{Scent marks as signals of the competitive} ability of opponents

Mammals can often gain information about the quality of potential opponents and mates from the quality of their odors, allowing them to discriminate against indi- viduals of low social rank, poor health or unsuitable genotype (reviewed by Brown \& Macdonald, 1985; Gosling \& Roberts, 2001a). Subordinate male house mice, for example, suppress production of competitive odors while living within the territory of a more dominant male, both in terms of the quality of their urinary odors and their deposition of urinary scent marks (Rich \& Hurst, 1998). Odor quality can also provide information on the relative competitive ability of partners living in social groups where individual social status and the production of odors reflecting status are controlled by competitive pressure (Roberts, 2007).

A close association between scent marking and social dominance was revealed in three gerbil species under study. Dominant males of tamarisk and midday gerbils in multi-male-multi-female breeding colonies as well as individuals of a higher social rank in family groups of the Mongolian gerbil were found to mark more frequently than subordinate individuals (Figs. 4 and 5).

High correlation between social rank and scent marking revealed both in the midday gerbil and the tamarisk gerbil (Gromov, 2000) supports the hypothesis that scent marking is involved in intra-sexual competition among males (Gosling \& Roberts, 2001a). As for the Mongolian gerbil, it needs to be emphasized that individuals possessing rank 1 and 2 (Fig. 5) are adult founders of family groups (males and females, respectively), and individuals possessing rank 3 and 4 are usually sub-adults of both sexes. Other members of family groups are young individuals of both sexes. Hence, in the case of the Mongolian gerbil, one can not talk about intra-sexual competition, and the high correlation between social rank and scent marking revealed in this species could be explained by the influence of other factors, e.g. hormonal and social ones related to delayed sexual maturation and reproductive suppression. In other words, a relationship between social rank and scent-marking activity in Mongolian gerbils seems to be not associated with status signaling only.

Observations under semi-natural conditions showed that females of midday and tamarisk gerbils mated with males irrespective of their social rank when presented with multiple potential mates. Hence, females of these gerbil species do not select mates according to the male's social rank. However, the higher-ranking males were found to mate with females more frequently than their lower-ranking opponents (Gromov, 2000). As for the Mongolian gerbil, suppressed production of competitive odors in younger, and hence subordinate individuals, could be explained by not only the influence of odors of dominant individuals, i.e. their parents, but a lower level of gonadal hormones as well. Besides, subordinate and young individuals in a family group of the Mongolian gerbil could not be regarded competitors for the territory and mates. As for scent marking exhibited by female Mongolian gerbils, it could not be only related to intra-sexual competition because of a familygroup mode of life of this species combined with the reproductive skew. 
A
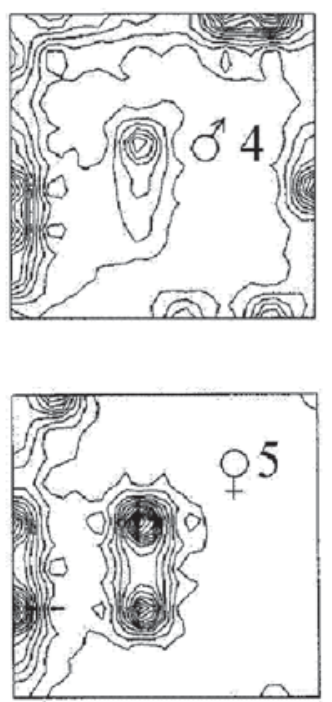
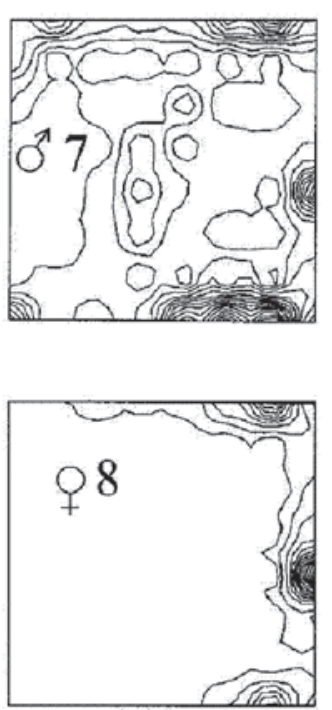

$B$
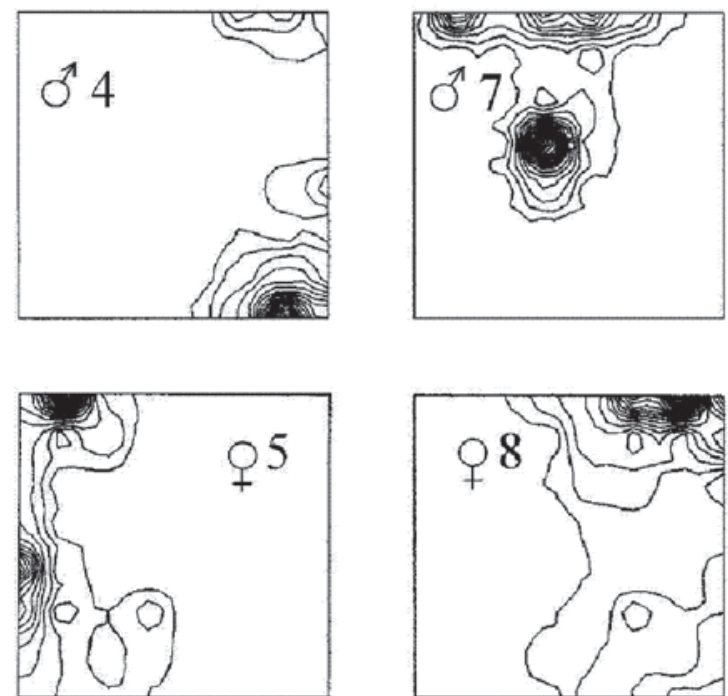

Figure 6. Contour mapping of the frequency of visual registration of tamarisk gerbils in the enclosure of $20 \times 20 \mathrm{~m}$. Contour lines connect points of equal frequency of registration per unit area (square $2.5 \times 2.5 \mathrm{~m}$ ). Higher density of the lines corresponds to the activity centers of the gerbils related to their nest burrows. A - summer (the mating season), B - autumn (after termination of reproduction).

\section{Spatial distribution of scent marks}

Irrespective of gerbil species, spatial distribution of their scent marks was found to be very uneven: within a home range, small loci with a higher quantity of scent marks along with relatively large areas with single marks or even without any marks were commonly found (Figs. 7, 9-11). Most scent-marking events were recorded in the environment near burrow entrances, along the pathways and the boundaries between neighboring home ranges (in case of the Mongolian gerbil).

Correlation analysis did not reveal a significant relationship between locations of the activity centers of the gerbils, related mainly to their nest burrows, and their scent-marking events (Gromov, 2000). In other words, the animals did not mark frequently the places which they used more intensive. Instead, both in the wild and the enclosures, gerbils have been observed to deposit ventral gland secretion and build up of 'signal heaps' in locations where others have left the same scent marks (Gromov, 2000). Gerbils often mark in the same vicinity as marks of conspecifics, and hence the animals are stimulated to mark by the scent of conspecifics. Such loci with an increased number of scent marks of several individuals might be called 'scentmarking centers'.

In male tamarisk gerbils, spatial distribution of scentmarking loci was found to vary in dependence on the phase of the breeding season. Observations of small groups consisting of two pairs of adults in large open enclosures (Figs. 6 and 7) have shown that males occupied larger ranges overlapping each other and ranges of females during the mating period, like in the wild (Fig. 6A). Scent-marking loci of the males were also found to overlap (Fig. 7A). The maximum number of scentmarking events of the males was recorded within the marking loci of the females. Besides, different female preference was revealed in the males: dominant male \# 4 actively marked exclusive ranges of both females (Fig. 7A), whereas subordinate male \# 7 marked more often the loci associated with the range of female \# 5 (Spearman correlation $\mathrm{R}=0.516, p=0.041$ ). Spatial distribution of 'signal heaps' of the gerbils was similar to that of ventral rubbing (Gromov 2000). Upon the end of the breeding season, males occupied exclusive areas within the enclosure, as in the wild (Fig. 6B), and their marking loci were found to be exclusive as well (Fig. 7B). Thus, spatial distribution of scent marks in male tamarisk gerbils was revealed to be dependent on the phase of breeding season and showed in accordance with seasonal changes in their space use system. Such a difference in distribution of scent-marking loci of males was equally typical of both main scent-marking patterns. Contrary to males, female tamarisk gerbils occupied mutually exclusive ranges during all seasons, like in the wild (Fig. 6A, B), and their marking loci usually did not overlap each other (Fig. 7A, B).

Similar spatial distribution of scent-marking events was found in the midday gerbil. Three groups consisting of 6 adult individuals of this species (each including 3 males and 3 females) were under observation in the enclosures during 5 months in the breeding season (Gromov, 2000). Males occupied totally overlapping 
A

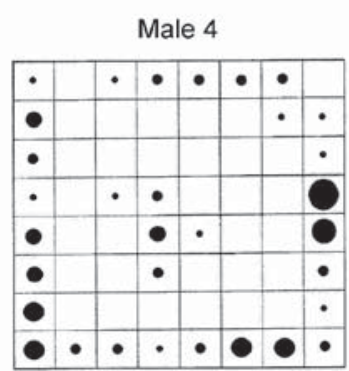

Female 5

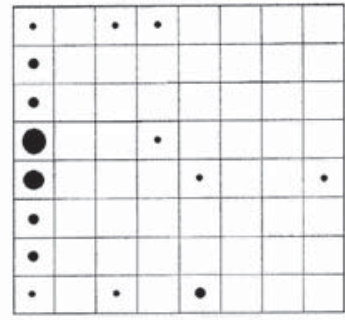

Male 4

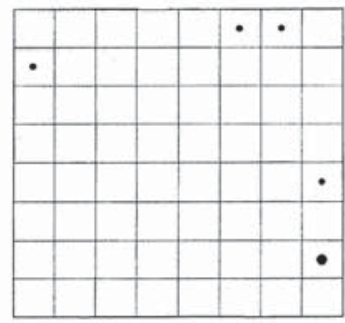

Female 5

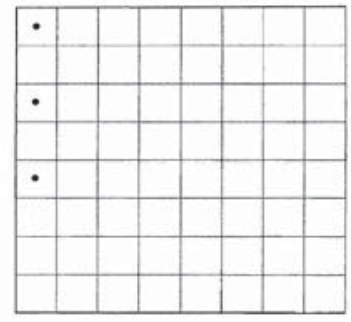

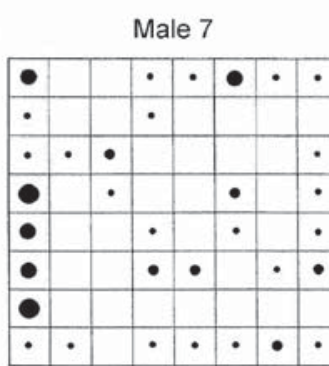

Female 8

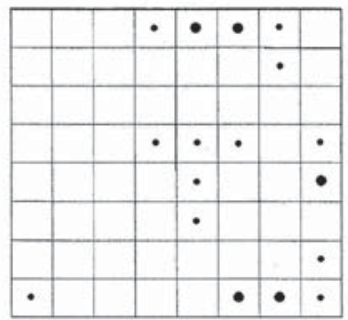

B

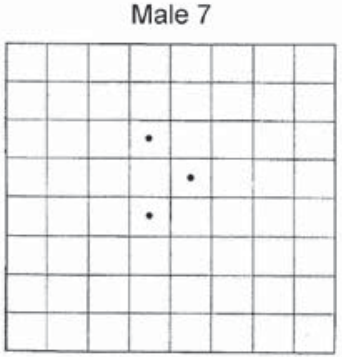

Female 8

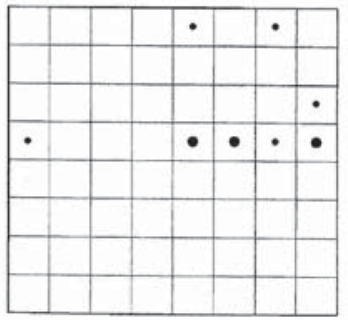

Figure 7. Spatial distribution of ventral-rubbing events recorded in squares of the enclosure of $20 \times 20 \mathrm{~m}$ in tamarisk gerbils. A - summer (total number of the events $n=379$ ), $\mathrm{B}$ - autumn (total number of the events $n=24$ ). Smallest dots indicate 1-2 scent-marking events, the largest spot 24 scent-marking events.

ranges in the enclosures, whereas females used ranges which core areas only partly overlapped (Fig. 8). Scentmarking loci of the males were found to overlap each other and scent-marking loci of the females (Fig. 9). However, some differences were revealed in the spatial distribution of scent-marking events of the males. For example, in one of the groups, dominant male \# 5 as well as sub-dominant male \# 2 exhibited a higher rate of ventral rubbing within the areas marked by all three females (Spearman correlations $\mathrm{R}>0.501, p<0.048$ ), whereas subordinate male \# 4 preferred to mark the
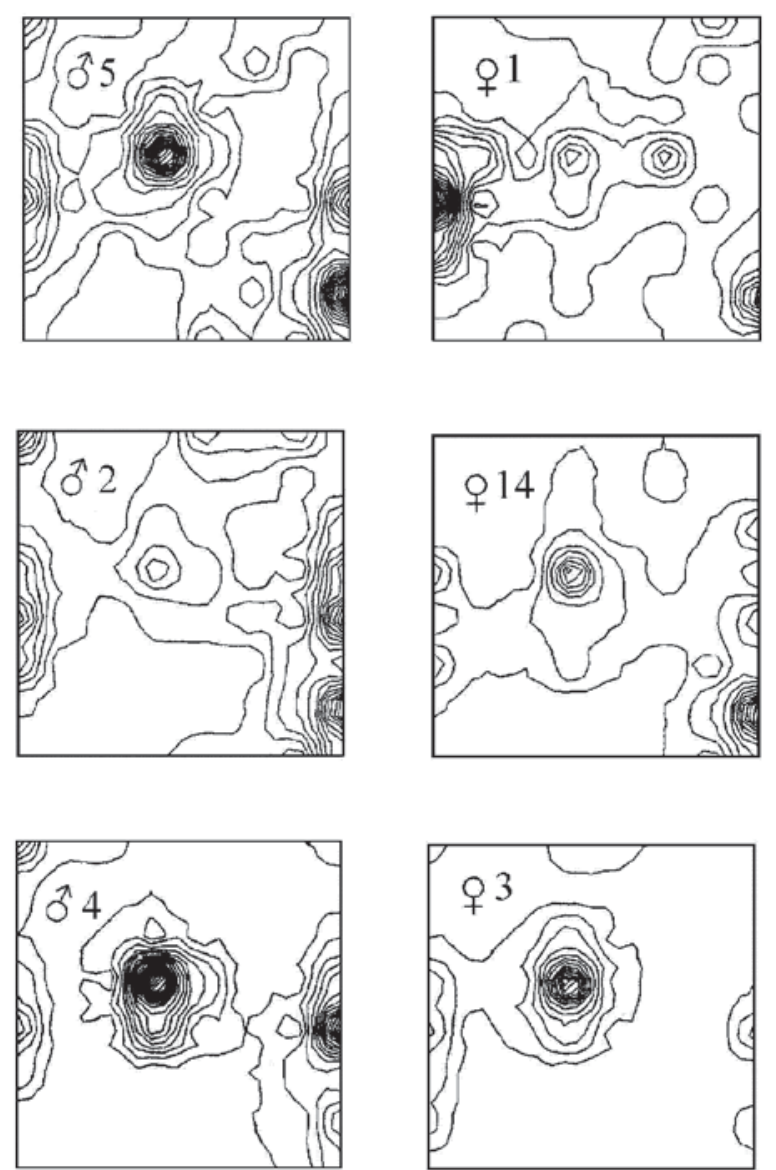

Figure 8. Contour mapping of the frequency of visual registration of midday gerbils in the enclosure of $20 \times 20 \mathrm{~m}$ during the observation period (June-August). Contour lines connect points of equal frequency of registration per unit area (square $2.5 \times 2.5 \mathrm{~m}$ ). Higher density of the lines corresponds to the activity centers of the gerbils related to their nest burrows.

only locus with maximum number of scent marks of female \# 3. As for the females, their scent-marking loci were found to be mutually exclusive (Fig. 9). Spatial distribution of scent-marking events of males and females of the midday gerbil was found to be similar for both ventral rubbing and building up of 'signal heaps' (Gromov 2000).

Females of all the species under study were most often found to mark the areas related to burrow entrances, pathways and feeding sites (Gromov, 2000). Besides, female Mongolian gerbils protecting their home ranges were revealed to mark some loci particularly strongly at the territorial boundaries with neighboring females where their scent marks were in close proximity (Fig. 10).

Males of all the species under study were found to exhibit a higher rate of scent marking within the home ranges of the females. In the Mongolian gerbil, if a family-group territory included the home ranges of two females, the frequency of scent marking in the adult male was much higher within the home range of a 


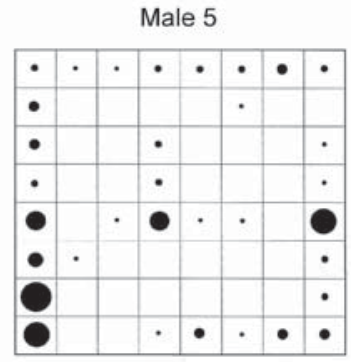

Male 2

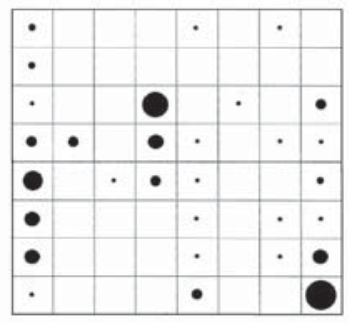

Male 4

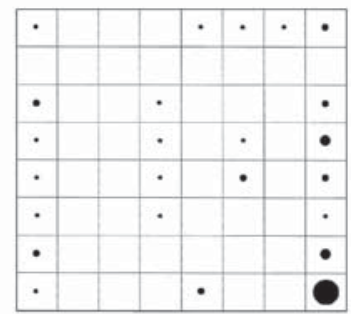

Female 1

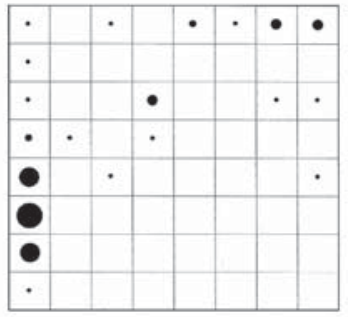

Female 14

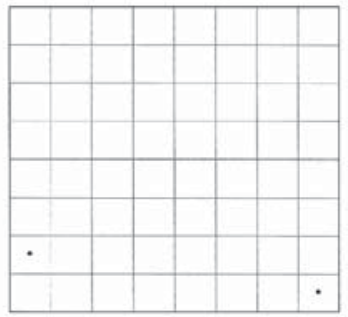

Female 3

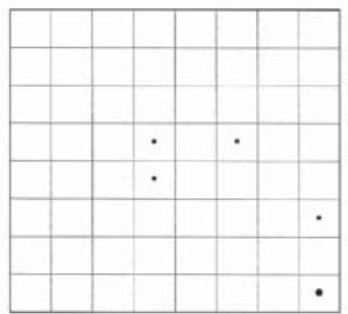

Figure 9. Spatial distribution of ventral-rubbing events (total number $n=427$ ) recorded in squares of the enclosure of $20 \times$ $20 \mathrm{~m}$ in midday gerbils during the observation period (JuneAugust). Smallest dots indicate1-2 scent-marking events, largest spots - 15-20 scent-marking events. receptive, pregnant or lactating female than in other places (Fig. 10). Neither males nor females of the Mongolian gerbil mark the periphery of their protected home ranges frequently except for the narrow overlap zone between neighboring territories.

With large home ranges, 'hinterland' marking could be more economical than marking of boundaries or overlap areas. An example of such a 'hinterland' marking is shown in Fig. 11 for females of the fat sand rat. Neither female nor male home ranges of this species have strongly established and protected boundaries. Females were found to place their scent marks mainly near their burrow entrances. In other words, female scent marking was confined to a central (core) area and was absent from a large peripheral zone. As for the dominant male, his scent marks were also found to be not randomly distributed. The male, whose large home range encompassed smaller ranges of four adult females, placed his scent marks mainly within the ranges of two reproducing females \# 2 and \# 3 (Fig. 11). I would like to emphasize that no scent-marking events of any intruders were recorded within the dominant male home range during the whole data collection period in October and November 1997. It means that scentmarking activity of the male was not dependent on corresponding activity of intruders.

Thus, during the breeding season, the spatial distribution of scent marks of males of all the species under study appears to be dependent mainly on the location of the home ranges of reproducing females and their scent marks. Upon the end of the breeding season, the relationship between spatial distribution of scent-marking events of males and females becomes weak or disappears, perhaps with the exception of Mongolian gerbils living in extended family groups. Differences in the

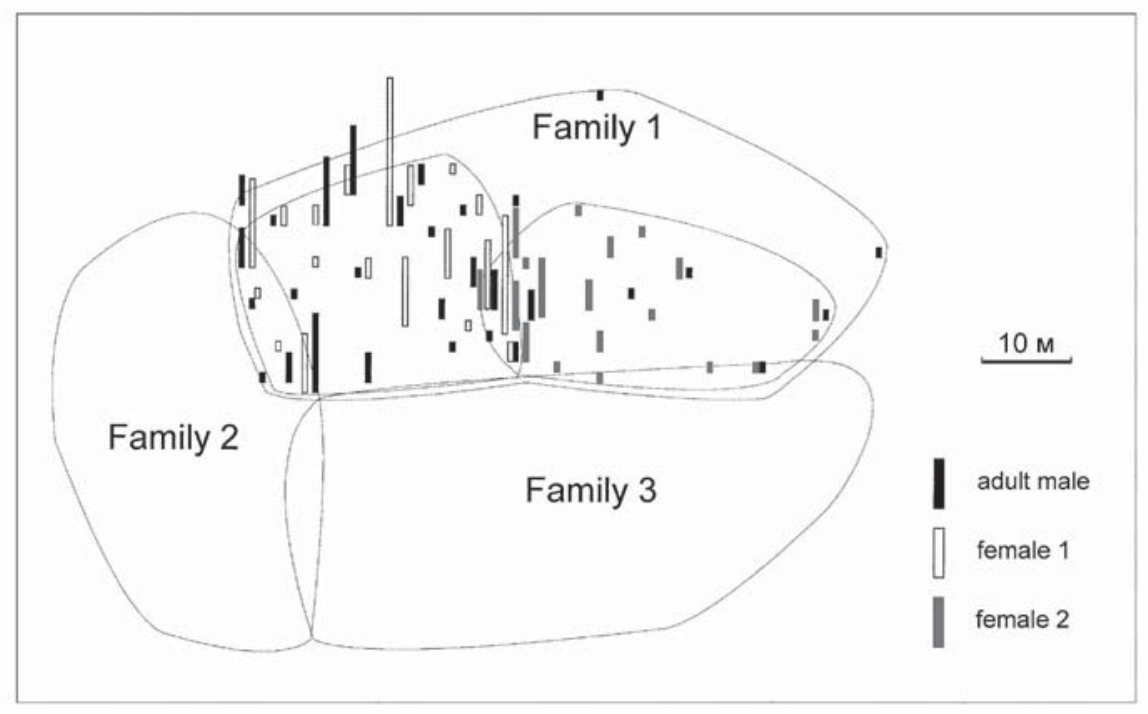

Figure 10. Spatial distribution of scent-marking events (building up of 'signal heaps', total number $n=277$ ) recorded during the observation period (July-August) within the family-group territory of Mongolian gerbils. The height of the bars is proportional to the number of scent-marking events. 


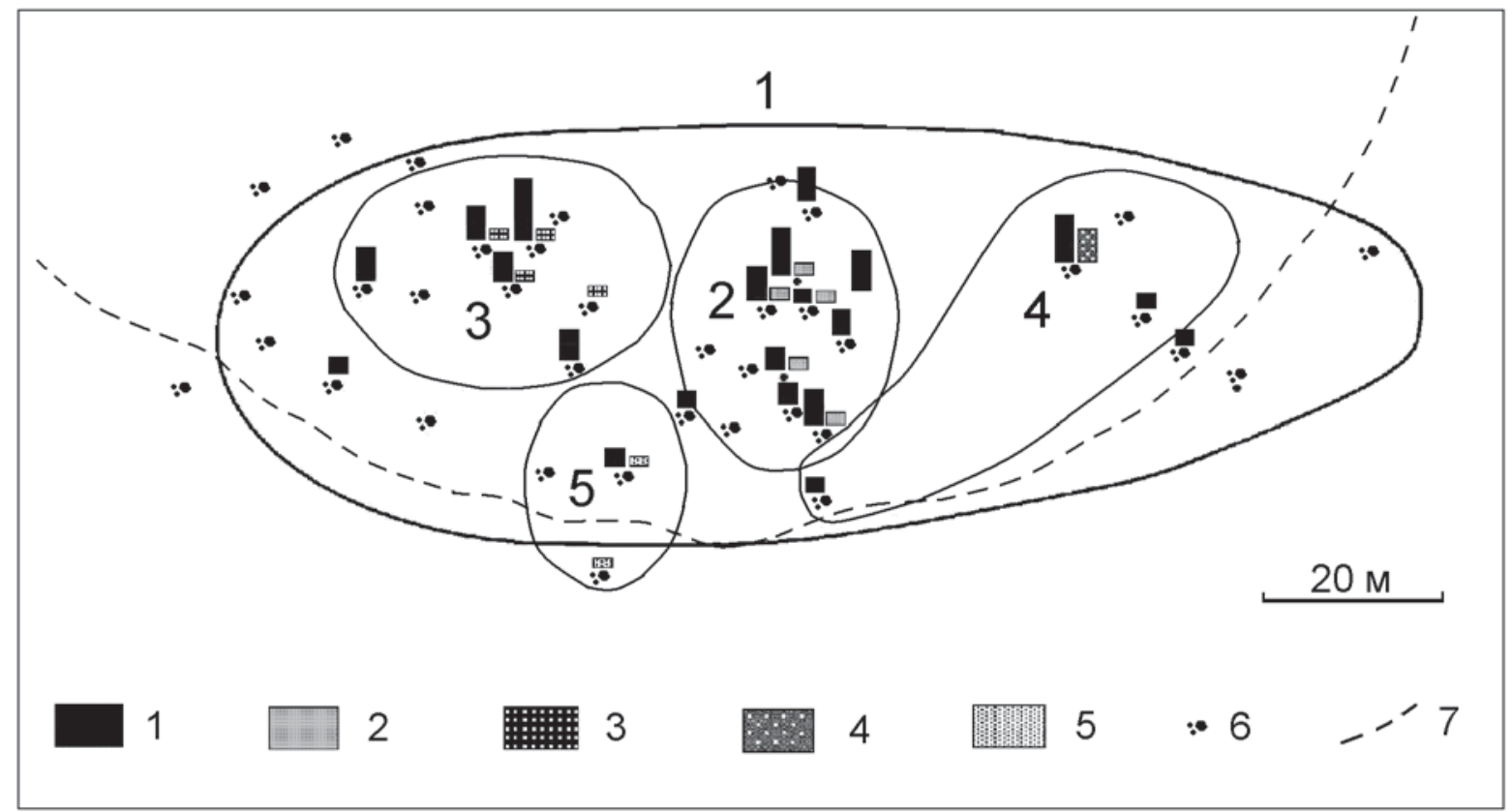

Figure 11. Spatial distribution of scent-marking events (building up of 'signal heaps', total number $n=70$ ) recorded during the observation period (October-November) in fat sand rats. The height of the bars is proportional to the number of scentmarking events. 1 - home range of the male (thick line) and his scent-marking events, $2-5$ - home ranges of the females (thin lines) and their scent-marking events, 6 - burrow entrances, 7 - the terrace border.

spatial patterns of scent marking existing between the Mongolian gerbil and the fat sand rat, as well as between other gerbil species (Gromov, 2000) might result from inter-specific variability of space use systems, and also from differences in their social and reproductive strategies.

\section{General discussion}

Observations in the wild and under semi-natural conditions have shown that the ventral rubbing and building up of 'signal heaps' are the main patterns of scent territorial marking in gerbils (Gromov, 1997, 2000, 2011a; Sokolov \& Gromov, 1998). The scent of ventral gland secretion is known to be individually distinctive (Halpin, 1974), and has been implicated in individual discrimination as well as in mate recognition (Halpin, 1974, 1986; Kumari \& Prakash, 1981a, b; Kittrell et al., 1982; Fullenkamp et al., 1985). Compared to scent of the ventral gland secretion, 'signal heaps' containing urine may convey more complex information indicating not only species and individual identity, but sex, age, social and reproductive status as well. Hence, building up of 'signal heaps' may have multiple functions.

Scent-marking activity of gerbils varies significantly depending on species, sex, age, reproductive conditions, social and territorial status of the individual, and shows pronounced seasonal variation (Thiessen et al., 1969; Whitsett \& Thiessen, 1972; Halpin, 1974; Prakash \& Kumari, 1979; Kumari \& Prakash, 1981a, b; Payman \& Swanson, 1981; Kittrell et al., 1982; Gromov, 1997,
2000, 2011a; Sokolov \& Gromov, 1998). The variability of scent-marking activity might be accounted for by a number of factors both stimulating and suppressing the scent-marking behavior. These factors could be divided into three main groups: hormonal, social and novelty. Factors of the first group cause stimulation of scent marking after reaching puberty as well as sexual dimorphism of scent marking and its seasonal dynamics. Factors of the second group cause stimulation of scent marking of high-ranking individuals and territory owners as well as suppression of scent marking in subordinate individuals and those ones that have lost their home ranges after territorial conflicts. Factors of novelty explain an increase of the marking activity of a resident individual after acquisition of its home range. All the factors equally affect both scent-making patterns in gerbils, i.e. ventral rubbing and the building up of 'signal heaps'.

A variety of functions have been proposed for ventral rubbing. Thiessen $(1968,1973)$ supposed that territorial signaling is of predominant importance of the ventral gland secretion although other functions, e.g. chemical communication, are not excluded. Prakash and Kumari (1979) have found that ventral rubbing is used for marking objects in the territory of the animal, and the dominant individual exhibited a greater rate of the ventral rubbing than those lower in the social hierarchy. Ventral rubbing thus may be associated with social status-signaling. Some other researchers (e.g., Naumov \& Goltsman, 1972) proposed that the ventral gland secretion produced by adults might be used for indication of a group odor. The functions of building up of 
'signal heaps' was not hypothesized. As mentioned above, the scent of ventral gland secretion is individually distinctive, whereas building up of 'signal heaps' may have multiple functions.

Generally, scent-marking functions seem to be related to three domains: (i) home range/territory and resource use and defense, (ii) social status and relationships, and (iii) reproductive function. According to Gosling (1982, 1990), scent marks in territories are best understood in terms of providing information for assessment by potential competitors (the scent-matching hypothesis). He suggested that scent marking allows an intruder to identify the territory owner by matching scent marks encountered in the territory with the scent of individuals encountered. Identification of the territory owner by the intruder can help to avoid escalating conflicts between them, and thus is beneficial to both parties. This theoretical model, being called the scentmatching hypothesis, predicts that scent marking should be increased in areas where scent marks are most likely to be encountered by an intruder, that is, along the territorial boundary (Gosling, 1982). Besides, a limited number of marks must generally be placed in such a way that they maximize the chance of intercepting the movements of intruders when intruders seek to reach the part of the territory that is most valuable to the owner (Gosling, 1981; Roberts \& Lowen, 1997).

The results of my studies concerning scent marking in gerbils are only partly consistent with Gosling's predictions because some theoretical expectations are not supported. For example, spatial clustering of marks toward territorial boundaries was not found in the Mongolian gerbil: both males and females of this species accumulated their marks in particular loci at the territorial borders with neighbors as well as inside their protected territories, but did not frequently mark the periphery zone, as did also females of the fat sand rat defending their home ranges. Besides, males of the midday gerbil as well as males of the tamarisk gerbil do not protect, but actively mark their home ranges, and the spatial distribution of their scent marks, as well as of scent marks of Mongolian gerbil males, appears to be dependent mainly on the spatial distribution of scent marks of conspecific females, especially of receptive ones, i.e. not related to activity and movements of intruders or competitors.

In his later work, Gosling (1990) proposed that the scent-matching hypothesis has a broader explanatory value assuming that scent matching is used by territorial and non-territorial species alike. Roberts (2007) developed a more generalized concept trying to explain many aspects of scent marking. According to this concept, that incorporates the scent-matching hypothesis, scent marks are status signals used in assessment by receivers, who are usually same-sexed conspecifics or potential mates. Status information carried by scent marks includes resource-holding potential, social status, hormonal and reproductive conditions. Status signaling is proposed to be a theoretical paradigm that explains almost all marking behavior (Gosling \& Roberts, 2001a, b; Roberts, 2007), and thus is regarded as a universal one.

The results of my studies do not contradict the status signaling hypothesis. Indeed, this hypothesis may account for a higher rate of scent marking of resource holders, difference in the rate of marking activity of high-ranking and low-ranking individuals, as well as territory owners and individuals that have lost their territories, and some other variations of scent marking. Nevertheless, the status signaling hypothesis could not be regarded as universal one. In particular, it does not predict spatial distribution of scent marks in gerbils, for example, predominant marking of home ranges of selected females by the males. Besides, it does not account for exhibition of scent marking in young individuals within family groups who can not be regarded either as resource holders or as potential mates, and does not answer the question of why adult Mongolian gerbils, being founders of the family groups, over-mark the scent of their mates and young offspring. This hypothesis also does not explain increased marking activity of gerbils induced by novelty factors, e.g. just after finding the sites with a removed upper layer of the ground that was observed in the enclosure experiments with both territorial and non-territorial species (Gromov, 2000). It is not clear why a resource holder has to leave several scent marks within a very small site during a very short period of time instead leaving there 1-2 scent marks that would be quite sufficient for status signaling. But such a response is quite understandable if the animal needs to saturate the area with its own scent. Thus, an increase of scent marking in response to novelty factors as well as exhibition of scent-marking activity by young gerbils are more consistent with the hypothesis of home range familiarization, proposed by Mykytowyzc $(1970,1974)$ and supported by some other researchers (Zhiqin, 1983; Ferron \& Ouellet, 1989; Walraven \& Van Elsacker, 1992). The enclosure experiments with gerbils that did not reveal significant difference in responses to novelty factors of individuals occupying unprotected home ranges (in $M$. meridianus) and defended territories (in M. unguiculatus) also support the hypothesis that the animals may use scent marking for home range familiarization.

The hypothesis interpreting scent marking as a means of familiarization of a home range merits special attention. Many researchers provided evidence that scent marking is a means to acquire and maintain the individual/group home range that is most important for reproducing individuals. For description of this phenomenon, they used such terms as 'personalization' (Thiessen, 1973), 'individualization' (Halpin, 1986) or 'familiarization' (Zhiqin, 1983; Ferron \& Ouellet, 1989; Walraven \& Van Elsacker, 1992), meaning that the saturation of territory with the animal own scent serves to make the area familiar. Besides, scent marks appear to assist in orientation of the resident within its territory and enhancing its confidence (Mykytowycz, 1970; Mykytowycz et al., 1976; Sandell, 1981; Richardson, 1991).

When familiarizing a new home range/territory, gerbils investigate and mark it with both ventral gland 
secretion and 'signal heaps'. The main factor stimulating the marking activity under such conditions is novelty. A home range owner tries to saturate the occupied area with its own odor as much as possible. This specific response has another reason: to enhance the resident's self-confidence which increases within a familiar environment and gives additional advantage to him when encountering intruders. The rate of scent marking negatively correlates to an extent of the home range familiarization and saturation of odorous background (Gromov, 2000). The maximum marking rate is observed at the first stage of home range familiarization. Later it declines and is maintained on a relatively stable level which is determined by hormonal and social stimulation. Under constant environmental conditions, temporary increase of marking activity is usually caused by periodical declines of intensity of familiar odor background due to the influence of external factors weakening or completely removing the odoriferous components of scent marks. Under such conditions, gerbils regularly over-mark their own scent marks and add new ones. Hence, marking activity could be considered a specific feedback response to a particular level of external stimulation. The increase of scent-marking activity of gerbils in the experiments with the presentation of novel scents is quite explainable because many scent marks are necessary to the home range owner to saturate the area with its own odor. Assuming that possession of a home range/territory is very important for any individual or a family group in any rodent species (Gromov, 2011a) scent marking could be also considered as a means of a range/territory monopolization.

In addition to the function of familiarization, the spatial distribution of scent marks in male gerbils supports the idea that scent marking could be used as a means of monopolization of reproducing females during the breeding season. Such a function of scent marking in gerbils, as well as other rodent species, has not been proposed before. As for females, their scent marking may be directed toward males rather than female competitors, and thus female marking is not associated with intra-sexual competition as was predicted by the status signaling hypothesis. By the way, this hypothesis accounts for the difference in the rate of scent marking of adult and sub-adult individuals, suggesting a link between scent-marking frequency and status (Roberts, 2007). But this difference could be also explained by a link between scent-marking behavior and production of gonadal hormones, and this explanation seems simpler and clear.

The spatial patterns of scent-marking events reported in this article suggest that scent marking functions mainly in intra-group communication. More specifically, a function in inter-sexual communication is suggested by the strong male-biased sexual dimorphism in rates of scent marking and by the preponderance of male responses to scent marks of females.

To summarize, I can conclude that scent marking in gerbils is a complex and multi-functional phenomenon.
Bearing in mind individual distinction of ventral gland secretion, the main function of ventral rubbing appears to be home range familiarization, whereas function of building up of 'signal heaps' seems to be multiple: home range familiarization, olfactory communication and status signaling. The main functions, however, do not exclude other, additional ones (for example, female monopolization); functions of two main scent-marking behaviors of gerbils supplement and duplicate each other to some extent. As for a theoretical model like the status signaling hypothesis (Gosling \& Roberts, 2001a, b; Roberts, 2007), it attracts by its simplicity, but could not account for all possible variations in scent-marking patterns and duplication of signals, and does not predict spatial distribution of scent marks in male gerbils. In general, scent marking of different gerbil species is characterized by a high degree of similarity, but, on the other hand, there are particular inter-species differences in scent marking related to specific features of the space use system, social structure, and reproductive strategy.

ACKNOWLEDGEMENTS. The study was supported by Russian Foundation for Basic Research (grants 9404-13130a, 02-04-48419a, 07-04-00142a, 11-04-00162a).

\section{References}

Ågren G., Zhou Q. \& Zhong W. 1989. Ecology and social behaviour of Mongolian gerbils, Meriones unguiculatus, at Xilinhot, Inner Mongolia, China // Animal Behaviour. Vol.37. P.11-27.

Brown R.E. \& Macdonald D.W. 1985. Social Odours in Mammals. Vols.1-2. Oxford: Clarendon Press. 468 p.

Daly M. \& Daly S. 1975. Behaviour of Psammomys obesus (Rodentia: Gerbillinae) in the Algerian Sahara // Zeitschrift für Tierpsychologie. Vol.39. P.298-321.

Dubyansky M.A. 1962. [On bodies of died individuals in colonies of the great gerbil] // Byulleten' Moskovskogo Obshchestva Ispytatelei Prirody. Otd. Biol. Vol.17. No.4. P.154 [in Russian].

Ferron J. \& Ouellet J.P. 1989. Behavioural context and possible function of scent marking by cheek rubbing in the red squirrel (Tamiasciurus hudsonicus) // Canadian Journal of Zoology. Vol.67. P.1650-1653.

Fullenkamp A., Fischer R.B., Vance R.A. \& Duffey K.A. 1985. The failure to demonstrate avoidance of ventral gland odors in male gerbils (Meriones unguiculatus) // Physiology and Behavior. Vol.35. P.763-765.

Gosling L.M. 1981. Demarkation in a gerenuk territory: an economic approach // Zeitschrift für Tierpsychologie. Vol.56. P.305-322.

Gosling L.M. 1982. A reassessment of the function of scent marking in territories // Zeitschrift für Tierpsychologie. Vol.60. P.89-118.

Gosling L.M. 1990. Scent marking by resource holders: alternative mechanisms for advertising the costs of competition // Macdonald D.W., Müller-Schwarze D. \& Natyncczuk S.E. (eds.). Chemical Signals in Vertebrates. Vol.8. Oxford: Oxford Univ. Press. P.315-328.

Gosling L.M. \& McKay H.V. 1990. Competitor assessment by scent-matching: an experimental test // Behavioral Ecology and Sociobiology. Vol.26. P.415-420.

Gosling L.M. \& Roberts S.C. 2001a. Scent-marking by male mammals: cheat-proof signals to competitors and mates // 
Advances in the Study of Behavior. Vol.30. P.169-217.

Gosling L.M. \& Roberts S.C. 2001b. Testing ideas about the function of scent marks in territories from spatial patterns // Animal Behaviour. Vol.62. P.F7-F10.

Gromov V.S. 1997. [Scent marking in gerbils: a comparative analysis of four Meriones species] // Zhurnal Obshchei Biologii. No.58. P.46-80 [in Russian, with English summary].

Gromov V.S. 2000. [Ethological Mechanisms of Population Homeostasis in Gerbils (Mammalia, Rodentia)]. Moscow: IPEE Press. 392 p. [In Russian, with English summary].

Gromov V.S. 2001. Day-time activities and social interactions in a colony of the fat sand rats, Psammomys obesus, at the Negev Highlands, Israel // Mammalia. Vol.65. P.13-28.

Gromov V.S. 2008. [Spatial-and-Ethological Population Structure in Rodents]. Moscow: KMK Sci. Press. 582 p. [In Russian, with English summary].

Gromov V.S. 2011a. Rodents and space: what behavior do we study under semi-natural and laboratory conditions? // Triunvery A. \& Scalise D. (eds.). Rodents: Habitat Pathology and Environmental Impact. New York: Nova Science Publishers. P.43-60.

Gromov V.S. 2011b. Parental Care, Tactile Stimulation and Sociality Evolution in Rodents: Behavioural, physiological and developmental aspects. Saarbrücken: LAP LAMBERT Academic Publishing. $104 \mathrm{p}$.

Halpin Z.T. 1974. Individual differences in the biological odors of the Mongolian gerbil (Meriones unguiculatus) // Behavioral Biology. Vol.11. P.253-259.

Halpin Z.T. 1986. Individual odors among mammals: origins and functions // Advances in the Study of Behavior. Vol.16. P.39-70.

Hediger H. 1949. Saügetier-Territorien und ihre Markierung // Bijdragen tot de Dierkunde. Vol. 28. P.172-184.

Johston R.E., Sorokin E.S. \& Ferkin M.H. 1997. Female voles discriminate males' over-marks and prefer topscent males // Animal Behaviour. Vol.54. P.679-690.

Kittrell E.M.W., Gregg B.R. \& Thiessen D.D. 1982. Brood patch function for the ventral scent gland of the female Mongolian gerbil, Meriones unguiculatus // Developmental Psychobiology. Vol.15. P.197-202.

Kumari S. \& Prakash I. 1981a. Scent-marking behaviour of Meriones hurrianae during oestrous // Animal Behaviour. Vol.29. P.1269-1271.

Kumari S. \& Prakash I. 1981b. Behavioural responses of Meriones hurrianae (Jerdon) to conspecific sebum of ventral sebaceous gland // Biology and Behavior. Vol.6. P.255-263.

Lindzey G., Thiessen D.D. \& Tucker A. 1968. Developmental and hormonal control of territorial marking in the male Mongolian gerbil (Meriones unguiculatus) // Developmental Psychobiology. Vol.1. P.97-99.

Mech S.G., Dunlap A.S. \& Wolff J.O. 2003. Female prairie voles do not choose males based on their frequency of scent-marking // Behavioral Processes. Vol.61. P.101-108.

Müller-Schwarze D. \& Heckman S. 1980. The social role of scent marking in beaver (Castor canadensis) // Journal of Chemical Ecology. Vol.6. P.81-95.

Mykytowycz R. 1970. The role of skin glands in mammalian communication // Johnston J.W., Moulton D.G. \& Turk A. (eds.). Advances in Chemoreception. I. Communication by Chemical Senses. New York: Appleton-CenturyCrofts. P.327-360.

Mykytowycz R. 1974. Odour in the spacing behaviour of mammals // Birch M.C. (ed.). Pheromones. Amsterdam: North-Holland. P.327-342.

Mykytowycz R., Hesterman E.R., Gambale S. \& Dudzinski M.L. 1976. A comparison of the effectiveness of the odors of rabbits, Oryctolagus cuniculus, in enhancing territorial confidence // Journal of Chemical Ecology. Vol.2. P.13-24.

Naumov N.P. \& Goltsman M.E. 1972. [Behavioral and physiological responses of mammals to conspecific odours] // Uspekhi Sovremennoi Biologii. Vol.73. P.427-443 [in Russian].

Owen K. \& Thiessen D.D. 1973. Regulation of scent marking in the female Mongolian gerbil Meriones unguiculatus // Physiology and Behavior. Vol.11. P.441-445.

Payman B.C. \& Swanson H.H. 1981. Scent marking and dominance in enclosure colonies of gerbils // Behavioral and Brain Research. Vol.2. P.271-272.

Popov S.V., Tchabovsky A.V., Shilova S.A. \& Shchipanov N.A. 1989. [Mechanisms of formation of the spatial-and-ethological population structure in the midday gerbil] // [Fauna and Ecology of Rodents]. Issue 17. P.5-57 [in Russian].

Prakash I. \& Kumari S. 1979. Occurrence of ventral marking gland in desert rodents // Säugetierkundliche Mitteilungen. Vol.27. P.315-316.

Rich T.J. \& Hurst J.L. 1998. Scent marks as reliable signals of the competitive ability of mates // Animal Behaviour. Vol.56. P.727-735.

Richardson P.R.K. 1991. Territorial significance of scent marking during the nonmating season in the Aardwolf Proteles cristatus (Carnivora: Protelidae) // Ethology. Vol.87. P.9-27.

Roberts S.C. 2007. Scent marking // Wolff J.O. \& Sherman P.W. (eds.). Rodent Societies - An Ecological \& Evolutionary Perspective. Chicago: Univ. Chicago Press. P.255-266.

Roberts S.C. \& Lowen C. 1997. Optimal patterns of scent marks in klipspringer (Oreotragus oreotragus) territories // Journal of Zoology. Vol.243. P.565-578.

Sandell M. 1981. Revirmarkering hos daggdjur // Fauna och Flora (Sver.). Vol.76. P.205-208.

Sokolov V.E. \& Gromov V.S. 1998. [Scent territory marking in gerbils (Mammalia, Rodentia)]. Moscow: IPEE Press. 216 p. [In Russian, with English summary].

Thiessen D.D. 1968. The roots of territorial marking in the Mongolian gerbil: A problem of species-common topography // Behavior Research Methods \& Instrumentation. Vol.1. P.70-76.

Thiessen D.D. 1973. Footholds for survival // American Scientist. Vol.61. P.346-351.

Thiessen D.D., Blum S.L. \& Lindzey G. 1969. A scentmarking response associated with the ventral sebaceous gland of the Mongolian gerbil, Meriones unguiculatus // Animal Behaviour. Vol.18. P.26-30.

Thomas S.A. 2002. Scent marking and mate choice in the prairie vole, Microtus ochrogaster // Animal Behaviour. Vol.63. P.1121-1127.

Thomas S.A. \& Wolff J.O. 2002. Scent marking in voles: a reassessment of counter marking, over marking, and selfadvertisement // Ethology. Vol.108. P.51-62.

Walraven V. \& Van Elsacker L. 1992. Scent-marking in New World primates: A functional review // Acta Zoologica et Pathologica Antverpiensia. Vol.82. P.51-59.

Whitsett J.M. \& Thiessen D.D. 1972. Sex differences in the control of scent marking behaviour in the Mongolian gerbil (Meriones unguiculatus) // Journal of Comparative and Physiological Psychology. Vol.78. P.381-385.

Zhiqin F. 1983. Ecological importance of the anal gland secretion of yellow voles (Lagurus luteus) // Chemical Signals in Vertebrates. Vol.3: Proc. 3rd International Symposium. Sarasota, Fla, April 11-13, 1982. New York - London. P.211-222. 